\title{
PRODUÇÃO DE MUDAS DE ERVA-MATE POR MINIESTAQUIA EM SUBSTRATOS RENOVÁVEIS
}

\author{
Dagma Kratz¹, Patrícia Pereira Pires², Carlos André Stuepp³, Ivar Wendling ${ }^{4}$ \\ ${ }^{1}$ Universidade Federal de Mato Grosso, Departamento de Engenharia Florestal, Cuiabá, Mato Grosso, Brasil - \\ dagkratz@yahoo.com.br \\ ${ }^{2}$ Universidade Federal de Goiás, Departamento de Engenharia Florestal, Goiânia, Goiás, Brasil - piresppatricia@ gmail.com \\ ${ }^{3}$ Universidade Federal do Paraná, Programa de Pós-Graduação em Agronomia, Curitiba, Paraná, Brasil - \\ carlosandrehc@hotmail.com \\ ${ }^{4}$ Empresa Brasileira de Pesquisa Agropecuária, Colombo, Paraná, Brasil - ivar.wendling @embrapa.br \\ Recebido para publicação: 28/05/2014 - Aceito para publicação: 05/03/2015
}

\begin{abstract}
Objetivou-se avaliar a viabilidade técnica da utilização de casca de arroz carbonizada (CAC), fibra de coco (FC), vermiculita média (VM) e substrato comercial à base de casca de pínus semidecomposta (SC) como componentes para formulação de substratos para produção de mudas de Ilex paraguariensis por miniestaquia, bem como as respectivas propriedades físicas e químicas das composições formadas e sua relação com as variáveis biométricas das mudas. Para tanto, foram formulados nove substratos, os quais tiveram suas propriedades físicas e químicas analisadas. Nas miniestacas, avaliaram-se: 1) a sobrevivência, número de raízes e comprimento da maior raiz na saída da casa de vegetação aos 90 dias; e 2) a sobrevivência na saída da casa de sombra aos 105 dias e 135 dias. Os substratos avaliados não apresentaram diferenças quanto à sobrevivência aos 90, 105 e 135 dias, com médias de 75\%, 62\% e $59 \%$, respectivamente. Para as características radiciais, os substratos com proporções balanceadas de fibra de coco e casca de arroz carbonizada propiciaram os melhores resultados. Todos os substratos testados mostraram-se favoráveis à produção de mudas de Ilex paraguariensis.

Palavras-chave: Clonagem; enraizamento adventício; Ilex paraguariensis; propagação vegetativa.
\end{abstract}

Resumo

\begin{abstract}
Yerba mate seedlings production by minicutting in renewable subtrates. We assess the technical viability of using carbonized rice husk (CAC), coconut fiber (CF), vermiculite (VM) and commercial substrate with semi-decomposed pine bark (SC) as components to formulate substrates for Ilex paraguariensis minicuttings production, as well as the physical and chemical properties of the formed compositions and its relation with biometric parameters of the formed plants. We formulated nine substrates, and analyzed their physical and chemical properties. In the minicuttings we evaluated: 1) survival, root number and length of roots in greenhouse at 90 days; 2) survival at the exit of shade house at 105 days and 135 days. The evaluated substrates showed no differences in survival at 90, 105 and 135 days, averaging 75\%, 62\% and 59\%, respectively. For root characteristics, the substrates with balanced proportions of coconut fiber and carbonized rice hulls showed the best results. All evaluated substrates can be recommended for Ilex paraguariensis minicuttings production. Keywords: Cloning; adventitious rooting; Ilex paraguariensis; vegetative propagation.
\end{abstract}

\section{INTRODUÇÃO}

A erva-mate (Ilex paraguariensis A. St.-Hil. - AQUIFOLIACEAE) é uma planta originária da América do Sul. Consumida habitualmente na Argentina, Paraguai, Uruguai e no Brasil, apresenta grande importância econômica, social e ecológica. Suas aplicações são variadas, predominando a produção de bebidas, como o chimarrão, o tererê e o chá-mate (COELHO et al., 2002; VIDOR et al., 2002). Essa espécie tem chamado a atenção da comunidade científica por seus efeitos benéficos à saúde humana, principalmente com relação à atividade antioxidante e protetora frente a processos degenerativos, como os que levam ao desenvolvimento de doenças cardiovasculares e a danos ao DNA (MACHADO et al., 2007).

Os plantios de erva-mate provenientes de sementes coletadas sem critérios técnicos apresentam desenvolvimento heterogêneo, com reflexos negativos na produtividade (DOMINGOS; WENDLING, 2006). Essas limitações podem ser minimizadas ou até mesmo extintas por meio da produção de mudas clonais de indivíduos geneticamente superiores (BRONDANI et al., 2009).

FLORESTA, Curitiba, PR, v. 45, n. 3, p. 609 - 616, jul. / set. 2015.

Kratz, D. et al.

ISSN eletrônico 1982-4688 / ISSN impresso 0015-3826

609

DOI: $10.5380 /$ rf.v45i3.36531 
O conhecimento dos fatores que influenciam no enraizamento de propágulos vegetativos é essencial para o sucesso da propagação clonal e, entre estes, o substrato utilizado tem participação direta, tendo como função sustentar e permitir um bom suprimento de oxigênio e água para a base da estaca e para o desenvolvimento do sistema radicial (HARTMANN et al., 2011; WENDLING et al., 2007b; BRONDANI et al., 2008). O substrato deve ser firme o suficiente para dar sustentação às raízes, entretanto, deve suprir, ao mesmo tempo, as necessidades de água e ar nesse ambiente. Com base nessas características, é essencial que se conheçam as propriedades físicas, químicas e biológicas desses materiais, garantindo, dessa forma, a qualidade das mudas formadas (VAVRINA et al., 2002).

No mercado, podem ser encontrados substratos prontos para produção de mudas, sendo os principais produtos comercializados à base de casca de pínus e turfa (CÁLDEIRA et al., 2011). Entretanto, atualmente destaca-se a baixa oferta de casca de pínus para fabricação de substratos, devido à competição com o mercado de energia e à diminuição de plantios do gênero Pinus no Brasil (ASSOCIAÇÃO BRASILEIRA DE PRODUTORES DE FLORESTAS PLANTADAS (ABRAF), 2013), enquanto que a principal desvantagem da turfa é o impacto ambiental, por se tratar de um material natural não renovável (CALDEIRA et al., 2011), aliada à proibição de sua importação temporária do Canadá, principal fornecedor de matéria-prima (MINISTÉRIO DA AGRICULTURA, PECUÁRIA E ABASTECIMENTO (MAPA), 2013).

Em lado oposto, encontra-se a casca de arroz, resíduo encontrado nas regiões produtoras de arroz e que vem sendo utilizada como componente de substratos, após passar pelo processo de carbonização, combinada com outros elementos, como fibra de coco, vermiculita e casca de pínus (KRATZ et al., 2012; SILVA et al., 2012). Segundo Couto et al. (2003), a baixa densidade da casca de arroz carbonizada é uma característica importante quando se deseja aumentar a porosidade total do substrato, proporcionando maior drenagem e uma melhor aeração ao sistema radicial da muda. É devido a sua alta macroporosidade que se faz necessária a sua combinação com elementos de maior microporosidade, como a fibra de coco e vermiculita (KRATZ et al., 2013).

Assim, considerando a importância do substrato e suas propriedades físico-químicas na produção de mudas, o presente trabalho objetivou avaliar a viabilidade técnica do uso de diferentes composições de substratos renováveis à base de casca de arroz carbonizada e fibra de coco para a produção de mudas de erva-mate via miniestaquia.

\section{MATERIAL E MÉTODOS}

\section{Preparo e análise dos substratos}

A base dos diferentes tratamentos de substratos foi a Fibra de Coco (FC) e a Casca de Arroz Carbonizada (CAC), ambos materiais renováveis, sendo o substrato comercial à base de casca de pínus e vermiculita (SC) e a Vermiculita Média (VM) utilizados para efeitos comparativos. Assim, foram formulados nove substratos (S), conforme as seguintes composições: S1 - 100\% SC; S2 - 50\% CAC + $50 \% \mathrm{VM} ; \mathrm{S} 3-80 \% \mathrm{FC}+20 \% \mathrm{CAC} ; \mathrm{S} 4-70 \% \mathrm{FC}+30 \% \mathrm{CAC} ; \mathrm{S} 5-60 \% \mathrm{FC}+40 \% \mathrm{CAC} ; \mathrm{S} 6-50 \% \mathrm{FC}$ $+50 \%$ CAC; $57-40 \%$ FC + 60\% CAC; S8 - 30\% FC + 70\% CAC; e S9 - 20\% FC + 80\% CAC.

Os componentes utilizados para a formulação dos substratos foram misturados manualmente, junto com a adubação de base $\left(6,6 \mathrm{~kg} \cdot \mathrm{m}^{-3}\right.$ de NPK 4-14-8; 3,3 kg.m $\mathrm{m}^{-3}$ de superfosfato simples $(20 \%$ de $\mathrm{P}_{2} \mathrm{O}_{5}$ e $14 \%$ de $\mathrm{SO}_{4}$ ) e $0,8 \mathrm{~kg} \cdot \mathrm{m}^{-3}$ de FTE-BR12 (9\% Zn, 3\% Fe, $2 \% \mathrm{Mn}, 0,1 \% \mathrm{Mo}, 1,8 \% \mathrm{~B}, 0,8 \% \mathrm{Cu}$ ). A caracterização física e química dos substratos foi realizada conforme a metodologia descrita na instrução normativa $\mathrm{n}^{\circ} 17$ (MAPA, 2007).

\section{Miniestaquia}

O experimento foi realizado no laboratório de Propagação de Espécies Florestais da Empresa

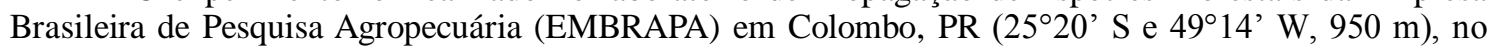
período de maio de 2011 a outubro de 2011.

Como fontes de propágulos para a miniestaquia, foram utilizadas minicepas de matrizes de ervamate com 12 anos de idade propagadas pelo processo convencional de estaquia (BRONDANI et al., 2007). As miniestacas foram coletadas e preparadas com $\pm 7 \mathrm{~cm}$, retirando-se o ápice e deixando um par de folhas com aproximadamente $1 / 3$ de sua área foliar inicial, sendo posteriormente tratadas com $3000 \mathrm{mg} . \mathrm{L}^{-1}$ de ácido indolbutírico (IBA). Em seguida, foram estaqueadas em tubetes de $55 \mathrm{~cm}^{3} \mathrm{com}$ a inserção de aproximadamente $2 \mathrm{~cm}$ da miniestaca nos diferentes substratos formulados (WENDLING et al., 2007b).

Após o plantio, as miniestacas foram acondicionadas em casa de vegetação com temperatura (20 a $30{ }^{\circ} \mathrm{C}$ ) e umidade relativa do ar (superior a $80 \%$ ) controladas automaticamente por termostato e umidostato, 
respectivamente, lá permanecendo por 90 dias. Decorrido esse período, o material foi transferido para casa de sombra 1 (50\% de sombreamento e irrigação por microaspersão, com três irrigações diárias com duração de 10 minutos e vazão de 144 L.hora $^{-1}$ ), onde permaneceu por 15 dias, sendo então transferido para casa de sombra 2 (40\% de sombreamento e irrigação por microaspersão, com duas irrigações diárias com duração de 5 minuto e vazão de 144 L.hora $^{-1}$ ), onde permaneceu por mais 30 dias.

Ao longo do experimento, avaliaram-se a sobrevivência das miniestacas na saída da casa de vegetação (SSCV), número de raízes (NR), comprimento da maior raiz na saída da casa de vegetação $(\mathrm{C}>\mathrm{R})$, comprimento total de raízes (CTR) e sobrevivência na saída da casa de sombra aos 105 (SSCS1) e 135 dias (SSCS2).

O delineamento experimental utilizado foi o inteiramente casualizado, com 9 tratamentos e 5 repetições contendo 16 miniestacas por unidade experimental. Inicialmente, os dados foram submetidos ao teste de Bartlett $(p<0,05)$, a fim de se verificar a homogeneidade de variância entre os tratamentos, e, em seguida, procedeu-se à análise de variância (ANOVA) $(p<0,05)$. De acordo com a significância da ANOVA, as médias foram comparadas pelo teste de Tukey $(p<0,05)$.

\section{RESULTADOS E DISCUSSÕES}

\section{Miniestaquia}

Observou-se efeito significativo ( $\mathrm{p}<0,01$ ) do substrato para as variáveis número de raízes $(\mathrm{NR})$, comprimento da maior raiz ( $\mathrm{C}>\mathrm{R})$ e comprimento total de raízes (CTR). Para a sobrevivência na saída de casa de vegetação (SSCV) e da casa de sombra aos 105 dias (SSCS1) e 135 dias (SSCS2), não houve diferença significativa (Tabela 1) entre as diferentes formulações de substrato, com médias de 75,1\%, $62,1 \%$ e $58,7 \%$, respectivamente, para SSCV, SSCS1 e SSCS2. Esses resultados indicam que todos os substratos avaliados apresentaram aptidão para a sobrevivência das miniestacas em casa de vegetação e de sombra. Ressalte-se que essa espécie florestal é de difícil enraizamento quando propagada por meio de materiais adultos (WENDLING et al., 2007b; BRONDANI et al., 2008, 2009).

Tabela 1. Sobrevivência na saída da casa de vegetação (SSCV), sobrevivência na saída da casa de sombra aos 105 (SSCS1) e 135 dias (SSCS2) de miniestacas de Ilex paraguariensis cultivadas em diferentes substratos.

Table 1. Survival at greenhouse exit (SSCV), survival in the shade house at 105 (SSCS1) and 135 days (SSCS2) for Ilex paraguariensis minicuttings grown on different substrates.

\begin{tabular}{llccc}
\hline \multirow{2}{*}{ Substrato } & SSCV & SSCS 1 & SSCS2 \\
\cline { 2 - 5 } & & \multicolumn{3}{c}{$\pm \mathbf{\sigma}$} \\
\hline 1. & SC & $73,3 \pm 4,7 \mathrm{a}$ & $58,6 \pm 14,4 \mathrm{a}$ & $50,6 \pm 17,3 \mathrm{a}$ \\
2. & $50 \mathrm{CAC} / 50 \mathrm{VM}$ & $81,5 \pm 14,4 \mathrm{a}$ & $75,4 \pm 22,6 \mathrm{a}$ & $68,7 \pm 21,0 \mathrm{a}$ \\
3. & $80 \mathrm{FC} / 20 \mathrm{CAC}$ & $76,7 \pm 13,4 \mathrm{a}$ & $60,2 \pm 27,7 \mathrm{a}$ & $58,8 \pm 30,9 \mathrm{a}$ \\
4. & $70 \mathrm{FC} / 30 \mathrm{CAC}$ & $74,6 \pm 21,2 \mathrm{a}$ & $57,3 \pm 30,0 \mathrm{a}$ & $57,3 \pm 25,6 \mathrm{a}$ \\
5. & $60 \mathrm{FC} / 40 \mathrm{CAC}$ & $68,4 \pm 17,2 \mathrm{a}$ & $49,4 \pm 15,3 \mathrm{a}$ & $48,1 \pm 15,9 \mathrm{a}$ \\
6. & 50FC/50CAC & $76,0 \pm 10,1 \mathrm{a}$ & $62,6 \pm 15,3 \mathrm{a}$ & $56,0 \pm 13,0 \mathrm{a}$ \\
7. & $40 \mathrm{FC} / 60 \mathrm{CAC}$ & $71,7 \pm 7,2 \mathrm{a}$ & $61,7 \pm 29,9 \mathrm{a}$ & $60,4 \pm 33,4 \mathrm{a}$ \\
8. & $30 \mathrm{FC} / 70 \mathrm{CAC}$ & $76,7 \pm 15,2 \mathrm{a}$ & $65,2 \pm 24,3 \mathrm{a}$ & $62,5 \pm 26,6 \mathrm{a}$ \\
9. & 20FC/80CAC & $77,3 \pm 7,6 \mathrm{a}$ & $68,0 \pm 5,5 \mathrm{a}$ & $65,3 \pm 2,9 \mathrm{a}$ \\
\hline
\end{tabular}

SC: substrato comercial à base de casca de pínus e vermiculita; VM: vermiculita média; FC: fibra de coco; CAC: casca de arroz carbonizada. Médias seguidas por mesma letra na coluna não diferem entre si pelo teste de Tukey, em nível de 5\% de probabilidade. б: desvio padrão em relação ao valor médio.

Brondani et al. (2008), utilizando composto de casca de arroz carbonizada e vermiculita média $(1: 1 \mathrm{v} / \mathrm{v})$, obtiveram resultados similares na miniestaquia de erva-mate, com média de $62,3 \%$ de sobrevivência em casa de vegetação aos 90 dias, para os diferentes clones avaliados. Para material juvenil, Wendling et al. (2007b) observaram maiores índices de sobrevivência para miniestacas obtidas de minicepas de origem seminal (propágulos juvenis), alcançando índices de até $90 \%$ de sobrevivência na saída da casa de vegetação.

Altos índices de sobrevivência e enraizamento podem estar associados à juvenilidade do material propagativo utilizado (HARTMANN et al., 2011; WENDLING et al., 2014). De acordo com Sand (1989), a erva-mate perde sua juvenilidade com cerca de três anos de idade. Com base nisso, pode-se destacar a eficiência da miniestaquia para a clonagem de genótipos adultos da espécie, visto que as

FLORESTA, Curitiba, PR, v. 45, n. 3, p. 609 - 616, jul. / set. 2015.

Kratz, D. et al.

ISSN eletrônico 1982-4688 / ISSN impresso 0015-3826

611

DOI: $10.5380 /$ rf.v45i3.36531 
minicepas utilizadas no presente estudo são de árvores matrizes com doze anos de idade. Diversos trabalhos constataram a influência da maturidade do material propagativo sobre a diminuição da capacidade de sobrevivência e enraizamento de miniestacas (WENDLING; XAVIER, 2005; BRONDANI et al., 2008, BITENCOURT et al., 2009).

Não foram verificadas diferenças significativas entre os substratos para a sobrevivência na saída da casa de sombra aos 105 dias $(62,1 \%)$ e 135 dias $(58,7 \%)$ (Tabela 1). Entretanto, nota-se uma redução nos valores de sobrevivência entre esses dois períodos, associada, possivelmente, ao estresse gerado pela variação na incidência luminosa, na SSCS1 com 50\% de bloqueio e na SSCS2 com 40\% de bloqueio, por meio de tela de sombreamento.

Do mesmo modo, a redução na SSCS1 aos 105 dias em comparação com a SSCV pode ser explicada pelo estresse gerado pelas mudanças nas condições ambientais às quais as miniestacas foram submetidas - regime hídrico e intensidade luminosa (BRONDANI et al., 2008). A aclimatação das miniestacas em casa de sombra acarreta quedas na taxa de sobrevivência, sendo que aquelas não enraizadas não conseguem se desenvolver no ambiente menos controlado, pois um sistema radicial não desenvolvido é incapaz de equilibrar as perdas hídricas promovidas pela evapotranspiração da brotação (ALMEIDA et al., 2007).

A miniestaquia aplicada à propagação de erva-mate tem apresentado diferentes respostas, associadas, em geral, às condições de produção e acondicionamento das miniestacas, sejam elas por meio da avaliação de diferentes condições nutricionais das minicepas ou mesmo pelo uso de diferentes substratos (WENDLING et al., 2007b; BRONDANI et al., 2007; 2009) e ambientes de enraizamento (BRONDANI et al., 2007; BRONDANI et al., 2009).

Ao se remeter às variáveis relacionadas ao vigor radicial (Tabela 2), verifica-se maior número de raízes por miniestaca do $\mathrm{S} 7 \quad(40 \mathrm{FC} / 60 \mathrm{CAC})$, sem diferença significativa em relação ao $\mathrm{S} 4$ (70FC/30CAC). Já para o comprimento da maior raiz, os melhores substratos foram o S2 (50CAC/50VM) e S4 (70FC/30CAC), sem diferença significativa em relação ao S1 (SC), S5 (50CAC/50VM) e S6 (40FC/60CAC). Para o comprimento total de raízes, S4 (70FC/30CAC) e S7 (40FC/60CAC) apresentaram os melhores resultados, embora somente com diferença significativa em relação aos substratos S3 (80FC/20CAC) e S9 (20FC/80CAC).

Tabela 2. Número de raízes (NR), comprimento da maior raiz (CMR) e comprimento total de raízes (CTR) na saída da casa de vegetação, de miniestacas de Ilex paraguariensis cultivadas em diferentes substratos.

Table 2. Number of roots (NR), longest root length (CMR) and total length of roots (CTR) of minicuttings at greenhouse exit grown on different substrates.

\begin{tabular}{|c|c|c|c|}
\hline \multirow{2}{*}{ Substrato } & \multirow{2}{*}{$\begin{array}{c}\text { NR } \\
\text { muda }^{-1} \pm \sigma\end{array}$} & CMR & CTR \\
\hline & & \multicolumn{2}{|c|}{$\mathrm{cm}^{-1} \pm \sigma$} \\
\hline 1. $\mathrm{SC}$ & $2,9 \pm 0,8 \mathrm{~cd}$ & $2,6 \pm 1,9 \mathrm{ab}$ & $5,5 \pm 4,7 a b c$ \\
\hline 2. $50 \mathrm{CAC} / 50 \mathrm{VM}$ & $3,1 \pm 0,8 \mathrm{~cd}$ & $3,2 \pm 2,0 \mathrm{a}$ & $7,3 \pm 4,6 a b$ \\
\hline 3. $80 \mathrm{FC} / 20 \mathrm{CAC}$ & $3,6 \pm 1,2 \mathrm{bcd}$ & $1,7 \pm 1,5 \mathrm{c}$ & $3,9 \pm 3,0 \mathrm{c}$ \\
\hline 4. $70 \mathrm{FC} / 30 \mathrm{CAC}$ & $4,5 \pm 2,3 \mathrm{ab}$ & $3,3 \pm 1,1 \mathrm{a}$ & $8,5 \pm 3,6 \mathrm{a}$ \\
\hline 5. $60 \mathrm{FC} / 40 \mathrm{CAC}$ & $3,6 \pm 1,0 \mathrm{bcd}$ & $2,7 \pm 0,8 \mathrm{ab}$ & $6,3 \pm 3,8 \mathrm{abc}$ \\
\hline 6. $50 \mathrm{FC} / 50 \mathrm{CAC}$ & $4,3 \pm 0,8 b c$ & $2,7 \pm 1,7 \mathrm{ab}$ & $8,0 \pm 3,4 a b$ \\
\hline 7. $40 \mathrm{FC} / 60 \mathrm{CAC}$ & $5,5 \pm 1,7 \mathrm{a}$ & $2,0 \pm 1,5 b c$ & $8,7 \pm 2,1 \mathrm{a}$ \\
\hline 8. $30 \mathrm{FC} / 70 \mathrm{CAC}$ & $4,0 \pm 1,1 \mathrm{bc}$ & $2,2 \pm 1,1 \mathrm{bc}$ & $5,9 \pm 4,2 \mathrm{abc}$ \\
\hline 9. $20 \mathrm{FC} / 80 \mathrm{CAC}$ & $2,7 \pm 1,8 \mathrm{~d}$ & $1,7 \pm 1,5 \mathrm{c}$ & $4,6 \pm 4,4 \mathrm{bc}$ \\
\hline
\end{tabular}

SC: substrato comercial à base de casca de pínus e vermiculita; VM: vermiculita média; FC: fibra de coco; CAC: casca de arroz carbonizada. Médias seguidas por mesma letra na coluna não diferem entre si pelo teste de Tukey, em nível de 5\% de probabilidade. б: desvio padrão em relação ao valor médio.

Os comportamentos diferenciados para as variáveis relacionadas ao vigor radicial analisados estão de acordo com estudo desenvolvido para estaquia de erva-mate (BRONDANI et al. 2009). Em termos comparativos para erva-mate, Bitencourt et al. (2009), utilizando como substrato VM e CAC $(1: 1 \mathrm{v} / \mathrm{v})$ em estacas rejuvenescidas, verificaram número maior de raízes $(13,2)$, porém semelhante ao comprimento médio das três maiores raízes $(2,8 \mathrm{~cm})$ encontrado nos melhores tratamentos do presente estudo. O maior número de raízes daquele estudo pode ser justificado pelo uso de bandejas como recipientes, e não tubetes, de modo que o maior volume pode ter contribuído para o maior número de raízes formadas. 
As concentrações médias de fibra de coco ou vermiculita podem ter colaborado para os maiores valores de comprimento da maior raiz, pois tais proporções favorecem uma condição de elevada umidade do substrato no interior do tubete, deslocando as raízes para as laterais dos mesmos e favorecendo, consequentemente, um alongamento das mesmas em busca de melhores condições de aeração. Uma aeração adequada é uma característica física imprescindível para o bom desenvolvimento de plantas em recipientes, conotando a necessidade de um equilíbrio entre água e ar para um bom desenvolvimento radicial (BEARDSELL et al., 1979; VERDONCK et al., 1981). A importância de se ter equilíbrio aeração/água pode ser verificada nos substratos que continham alta ou baixa proporção da fibra de coco, pois foram os que apresentaram os menores valores de características radiciais (Tabela 2).

Os resultados apresentados demonstraram a importância de se avaliar diferentes composições para formulações de substratos, podendo recomendar para determinada espécie ou clone o substrato mais adequado.

\section{Propriedades físicas e químicas dos substratos}

De maneira geral, observou-se que a adição de casca de arroz carbonizada (CAC) à fibra de coco (FC) aumentou o potencial hidrogeniônico, a densidade aparente, a porosidade total e a macroporosidade, diminuindo a microporosidade, a água facilmente disponível, a condutividade elétrica e o teor total de sais solúveis (Tabela 3).

Tabela 3. Resultados da análise física e química dos diferentes substratos utilizados para miniestaquia de Ilex paraguariensis. Potencial hidrogeniônico $(\mathrm{pH})$, condutividade elétrica $(\mathrm{CE})$, teor total de sais solúveis (TTSS), densidade aparente (Da), porosidade total $(\mathrm{Pt})$, macroporosidade (Macro), microporosidade (Micro) e água facilmente disponível (AFD).

Table 3. Results of physical and chemical analysis of different substrates used to produce Ilex paraguariensis minicuttings. Hydrogenic potential $(\mathrm{pH})$, electrical conductivity $(\mathrm{CE})$, total content of soluble salts (TTSS), apparent density (Da), total porosity (Pt), macroporosity (Macro), microporosity (Micro) and readily available water (AFD).

\begin{tabular}{|c|c|c|c|c|c|c|c|c|}
\hline \multirow{2}{*}{ Substratos } & \multirow{2}{*}{$\begin{array}{c}\mathbf{p H} \\
\mathrm{H}_{2} \mathrm{O}\end{array}$} & \multirow{2}{*}{$\begin{array}{c}\text { CE } \\
\text { mS.cm }\end{array}$} & \multirow{2}{*}{$\begin{array}{l}\text { TTSS } \\
\text { g.L } L^{-1}\end{array}$} & \multirow{2}{*}{$\begin{array}{c}\mathrm{Da} \\
\mathrm{kg} \cdot \mathrm{m}^{3}\end{array}$} & $\mathbf{P t}$ & Macro & Micro & AFD \\
\hline & & & & & \multicolumn{4}{|c|}{$\%$} \\
\hline $\mathrm{SC}$ & 5,47 & 1,53 & 5,86 & 398 & 79 & 19 & 60 & 24 \\
\hline $50 \mathrm{CAC} / 50 \mathrm{VM}$ & 7,92 & 0,06 & 0,09 & 183 & 72 & 37 & 35 & 9 \\
\hline $80 \mathrm{FC} / 20 \mathrm{CAC}$ & 6,23 & 1,09 & 1,12 & 89 & 85 & 36 & 49 & 20 \\
\hline 70FC/30CAC & 6,39 & 0,96 & 1,21 & 86 & 84 & 38 & 46 & 18 \\
\hline $60 \mathrm{FC} / 40 \mathrm{CAC}$ & 6,70 & 0,73 & 0,90 & 89 & 86 & 45 & 41 & 17 \\
\hline $50 \mathrm{FC} / 50 \mathrm{CAC}$ & 7,12 & 0,54 & 0,63 & 96 & 90 & 57 & 33 & 13 \\
\hline $40 \mathrm{FC} / 60 \mathrm{CAC}$ & 7,00 & 0,62 & 0,76 & 93 & 90 & 55 & 35 & 14 \\
\hline $30 \mathrm{FC} / 70 \mathrm{CAC}$ & 7,06 & 0,62 & 0,74 & 96 & 90 & 54 & 36 & 15 \\
\hline 20FC/80CAC & 7,59 & 0,36 & 0,41 & 101 & 89 & 62 & 27 & 12 \\
\hline
\end{tabular}

SC: substrato comercial à base de casca de pínus e vermiculita; VM: vermiculita média; FC: fibra de coco; CAC: casca de arroz carbonizada.

Dentre as propriedades químicas do substrato, o índice de acidez $(\mathrm{pH})$ se destaca, sobretudo pelos danos causados em função de seu desequilíbrio, ocasionando injúrias, ou de forma indireta afetando a disponibilidade de nutrientes e produzindo condições bióticas desfavoráveis (WALLER; WILSON, 1984). Valores ideais de $\mathrm{pH}$ para fins de cultivo hortícola se enquadram em uma faixa entre 5,0 e 5,8 para substratos com predomínio de matéria orgânica e, entre 6,0 e 6,5 para substratos com predomínio de solo mineral (KÄMPF; FERMINO, 2000). Neste contexto, apenas S1 (5,5), S3 $(6,2)$ e S4 $(6,4)$ apresentaramse adequados para a produção de mudas. Entretanto, deve-se ressaltar que apesar das diferenças verificadas, o mesmo não influenciou no processo de enraizamento e consequente sobrevivência destas mudas, uma vez que não foram obtidas diferenças significativas entre os diferentes tratamentos para estas variáveis. É importante salientar que um valor ideal de $\mathrm{pH}$ tende a variar sempre em função da espécie estudada, sendo a erva-mate naturalmente exigente em solos mais ácidos (SANTIN et al., 2013).

Já para a condutividade elétrica (CE), com exceção de S1 (comercial) e S3 (80FC/20CAC), todos os demais substratos se apresentaram dentro da faixa ideal, ou seja, abaixo de $1,0 \mathrm{mS} \mathrm{cm} \mathrm{cm}^{-1}$ recomendada (GONÇALVES et al., 2000) (Tabela 3). Em ambos os casos, foi possível verificar que à medida que se ampliavam as concentrações de CAC houve redução nos valores para TTSS e CE. Este

FLORESTA, Curitiba, PR, v. 45, n. 3, p. 609 - 616, jul. / set. 2015.

Kratz, D. et al.

ISSN eletrônico 1982-4688 / ISSN impresso 0015-3826

DOI: $10.5380 /$ rf.v45i3.36531 
resultado encontra-se em acordo com os verificados por Schmitz et al. (2002), que observaram valores reduzidos para TTSS em CAC. Segundo Conover (1967), a faixa ideal de TTSS para substratos hortícolas está entre 0 e $0,5 \mathrm{~g} \mathrm{~L}^{-1}$. Baseado nestes parâmetros, apenas $\mathrm{S} 2$ (50CAC/50VM) com $0,09 \mathrm{~g} \mathrm{~L}^{-1}$ e S9 (20FC/80CAC) com $0,41 \mathrm{~g} \mathrm{~L}^{-1}$ se enquadraram como adequados para cultivo, com destaque para $\mathrm{S} 1$ (comercial) com 5,86 g L-1 (Tabela 3).

A densidade aparente (Da) dos substratos variou de $86 \mathrm{~kg} \mathrm{~m}^{-3}$ no S4 (70FC/30CAC) a $398 \mathrm{~kg} \mathrm{~m}^{-3}$ no S1 (SC) (Tabela 3). Se considerada a densidade ideal para cultivo hortícola entre $400 \mathrm{~kg} \mathrm{~m}^{-3}$ e $500 \mathrm{~kg}$ $\mathrm{m}^{-3}$ (BUNT, 1973), apenas S1 (comercial) estaria próximo a esta faixa. O S2 (50CAC/50VM) apresentou um valor intermediário para densidade e os demais tratamentos compostos por diferentes proporções de FC e CAC, apresentaram valores baixos para densidade, entre $86 \mathrm{~kg} \mathrm{~m}^{-3} \mathrm{e} 101 \mathrm{~kg} \mathrm{~m}^{-3}$, diminuindo à medida que se ampliavam as proporções de fibra de coco ao substrato. Mesmo com a utilização da recomendação de Kämpf (2005), ou seja, faixa recomendada entre $100 \mathrm{~kg} \mathrm{~m}^{-3}$ e $300 \mathrm{~kg} \mathrm{~m}^{-3}$, apenas o S2 e S9 estariam dentro desta faixa. Entretanto, é importante ressaltar que, apesar da baixa densidade verificada nos diferentes tratamentos, esta variável não apresentou efeito sobre a sobrevivência das miniestacas em nenhuma das avaliações (Tabela 1).

De acordo com Carrijo et al. (2002), um substrato ideal deve apresentar uma porosidade total acima de $85 \%$, correspondendo com os resultados verificados no presente estudo, onde, com exceção do $\mathrm{S} 1$ (SC) e do S2 (50CAC/50VM), todos os demais se enquadraram perfeitamente.

Uma relação adequada entre macro e microporos é essencial para que haja um bom desenvolvimento das mudas nos recipientes (LOPES et al., 2005). Desta forma, para obter bons resultados na produção de mudas, almejam-se valores adequados de porosidade total entre $75-85 \%$, macroporosidade entre 35-45\% e microporosidade entre 45-55\% (MAEDA et al., 2007). Valores de macroporosidade considerados adequados foram verificados em trabalhos com erva-mate variando de $38,3 \%$ a $42,8 \%$, observados em tratamentos que continham como componentes palitos de erva-mate e/ou serragem (WENDLING et al., 2007a). Os valores adequados para macroporosidade foram verificados no presente experimento no S2 (50 CAC/50VM), S3 (80 FC/20CAC), S4 (70FC/30CAC) e S5 (60FC/40CAC), variando de $36 \%$ a $45 \%$.

O aumento nas concentrações de CAC nos substratos avaliados foi responsável pela elevação da macroporosidade, de $36 \%$ no S3 (80FC/20CAC) para $62 \%$ no S9 (20FC/80CAC), conotando a importância deste componente na obtenção de uma boa drenagem no substrato. Com relação à microporosidade, pode-se observar elevada porcentagem de microporos no S1 (SC) e nas maiores proporções de FC no substrato. A microporosidade dos substratos pode favorecer as características de retenção de água (LOPES et al., 2005) e, portanto, a utilização de FC como componente em substratos com menor capacidade de retenção de água pode refletir na redução da necessidade de irrigações, sobretudo em épocas com menores taxas de transpiração (KRATZ et al., 2012). Entretanto, sua utilização deve estar sempre associada a condições de irrigação adequadas, a fim de evitar danos à qualidade das mudas produzidas (ZANETTI et al., 2003).

Resultados similares ao presente estudo foram observados por Schmitz et al. (2002), os quais verificaram que a medida que se ampliava as concentrações de CAC e reduzia as de turfa, sanavam-se os problemas relacionados ao excesso de umidade deste material orgânico. A adição de CAC favorece o aumento de macroporos em detrimento dos microporos, melhorando as condições de drenagem (TSAKALDIMI, 2006; SILVA et al., 2012; KRATZ et al., 2013).

\section{CONCLUSÕES}

- Todos os substratos avaliados são tecnicamente viáveis para a produção de mudas de Ilex paraguariensis, embora aqueles que continham proporções balanceadas de fibra de coco e casca de arroz carbonizada tenham proporcionado melhores características radiciais.

- Mesmo os substratos avaliados não se enquadrando em todos os índices recomendados pela literatura, com relação às suas características físicas e químicas, eles podem ser usados para a produção de mudas de Ilex paraguariensis, não interferindo na sua aptidão de uso.

\section{REFERÊNCIAS}

ALMEIDA, F. D. de; XAVIER, A.; DIAS, J. M. M. Propagação vegetativa de árvores selecionadas de Eucalyptus cloeziana F. Muell. por estaquia. Revista Árvore, Viçosa, v. 31, p. 445 - 453, 2007. 
ASSOCIAÇÃO BRASILEIRA DE PRODUTORES DE FLORESTAS PLANTADAS (ABRAF). Anuário estatístico da ABRAF 2013, ano base 2012 / ABRAF. Brasília, 2013. 148 p.

BEARDSELL, D. V.; NICHOLS, D. G.; JONES, D. L. Physical properties of nursery potting-mixtures. Scientia Horticulturae, Amsterdam, v. 11, p. 1 - 8, 1979.

BITENCOURT, J.; ZUFFELLATO-RIBAS, K. C.; WENDLING, I.; KOEHLER, H. S. Enraizamento de estacas de erva-mate (Ilex paraguariensis A. St.-Hill.) provenientes de brotações rejuvenescidas. Revista Brasileira de Plantas Medicinais, Botucatu, v. 11, p. 277 - 281, 2009.

BRONDANI, G. E.; WENDLING, I.; ARAÚJO, M. A.; SANTIN, D.; BENEDETTI, E. L.; ROVEDA, L. F. Composições de substratos e ambientes de enraizamento na estaquia de Ilex paraguariensis A. St.-Hil. Revista Floresta, Curitiba, v. 39, p. 41 - 49, 2009.

BRONDANI, G. E.; WENDLING, I.; SANTIN, D.; BENEDETTI, E. L.; ROVEDA, L. F.; ORRUTÉA, A. G. Ambientes de enraizamento e substratos na miniestaquia da erva-mate. Scientia Agraria, Curitiba, v. 8, p. 257 - 267, 2007.

BRONDANI, G. E.; ARAUJO, M. A.; WENDLING, I.; KRATZ, D. Enraizamento de miniestacas de erva-mate sob diferentes ambientes. Pesquisa Florestal Brasileira, Colombo, n. 57, p. 29 - 38, 2008.

BUNT, A. C. Some physical and chemical characteristics of loamless pot-plant substrates and their relation to plant growth. Plant and Soil, The Hague, n. 38, p. 1954 - 1965, 1973.

CALDEIRA, M. V. W.; WENDLING, I.; PENCHEL, R. M.; GONÇALVES, E. O.; KRATZ, D.; TRAZZI, P. A. Propriedades de substratos para produção de mudas florestais. In: CALDEIRA, M. V. W.; GARCIA, G. O.; GONÇALVES, E. O.; ARANTES, M. D. C.; FIEDLER, N. C. Contexto e perspectivas da área florestal no Brasil. Alegre, ES: Suprema, 2011, p. 141 - 160.

CARRIJO, O. A.; LIZ, R. S.; MAKISHIMA, N. Fibra de casca de coco verde como substrato agrícola. Horticultura Brasileira, Brasília, v. 20, p. 533 - 535, 2002.

COELHO, G. C.; MARIATH, J. E. de A.; SCHENKEL, E. P. Populational diversity on leaf morphology of mate (Ilex paraguariensis A. St.-Hil., Aquifoliaceae). Brazilian Archives of Biology and Technology, Curitiba, v. 45, p. 47 - 51, 2002.

CONOVER, S. A. Soil mixes for ornamental plants. Florida Flower Grower, Florida, v. 4, p. 1 - 4, 1967.

COUTO, M.; WAGNER JÚNIOR, A.; QUEZADA, A. C. Efeito de diferentes substratos durante a aclimatização de plantas micropropagadas do porta-enxerto mirabolano 29c (Prunus cerasifera Ehrh.) em casa de vegetação. Revista Brasileira de Agrociência, Pelotas, v. 9, p. 125 - 128, 2003.

DOMINGOS, D. M.; WENDLING, I. Sobrevivência e vigor vegetativo de plantas de erva-mate (Ilex paraguariensis A. St.-Hil.) enxertadas diretamente a campo. Ciência Florestal, Santa Maria, v. 16, p. 107 - 112, 2006.

GONÇALVES, J. L. M.; SANTARELLI, E. D.; MORAES NETO, S. P. de; MANARA, M. P. Produção de mudas de espécies nativas: substrato, nutrição, sombreamento e fertilização. In: GONÇALVES, J. L. M.; BENEDETTI, V. (Ed.). Nutrição e fertilização florestal. Piracicaba: IPEF, 2000. p. 309 - 350.

HARTMANN, H. T.; KESTER, D. E.; DAVIES JR., F. T.; GENEVE, R. Plant propagation: principles and practices. 8th. ed. Boston: Prentice-Hall, 2011.915 p.

KÄMPF, A. N. Substrato. In: KAMPF, A. N. Produção comercial de plantas ornamentais. 2. ed. Guaíba: Agrolivros, 2005. p. 45 - 72.

KÄMPF, A. N.; FERMINO, M. H. Substratos para plantas: a base da produção vegetal em recipientes. Porto Alegre: Genesis, 2000. 312 p.

KRATZ, D.; WENDLING, I.; PIRES, P. P. Miniestaquia de Eucalyptus benthamii x E. dunnii em substratos à base de casca de arroz carbonizada. Scientia Forestalis, Piracicaba, v. 40, n. 96, p. 547 - 556, 2012.

KRATZ, D.; WENDLING, I.; NOGUEIRA, A. C.; SOUZA, P. V. de. Propriedades físicas e químicas de substratos renováveis. Revista Árvore, Viçosa, v. 37, p. 1103 - 1113, 2013.

LOPES, J. L. W.; GUERRINI. I. A.; SAAD, J. C. C.; SILVA, M. R. Efeitos da irrigação na sobrevivência, transpiração e no teor relativo de água na folha em mudas de Eucalyptus grandis em diferentes substratos. Scientia Forestalis, Piracicaba, v. 68, p. 97 - 106, 2005. 
MACHADO, C. C. B.; BASTOS, D. H. M.; JANZANTTI, N. S.; FACANALI, R.; MARQUES, M. O. M.; FRANCO, M. R. B. Determinação do perfil de compostos voláteis e avaliação do sabor e aroma de bebidas produzidas a partir da erva-mate (Ilex paraguariensis). Química Nova, São Paulo, v. 30, p. 513 $518,2007$.

MAEDA, S.; DEDECEK, R. A.; AGOSTINI, R. B.; ANDRADE, G. C.; SILVA, H. D. Caracterização de substratos para produção de mudas de espécies florestais elaborados a partir de resíduos orgânicos. Pesquisa Florestal Brasileira, Colombo, n. 54, p. 97 - 104, 2007.

MINISTÉRIO DA AGRICULTURA, PECUÁRIA E ABASTECIMENTO (MAPA). Instrução Normativa SDA $\mathbf{N}^{0}$ 17. Diário Oficial da União - Seção 1, $\mathbf{n}^{\circ}$ 99, 24 de maio de 2007. Métodos Analíticos Oficiais para Análise de Substratos para Plantas e Condicionadores de Solo. Brasília, 2007.

MINISTÉRIO DA AGRICULTURA, PECUÁRIA E ABASTECIMENTO (MAPA). Instrução Normativa SDA no 3. Diário Oficial da União - Seção 1, nº 2.200-2 de 24/08/2001. Brasília, 2013.

SAND, H. A. Propagación agámica de la yerba-mate (Ilex paraguariensis St. Hil.). Cerro Azul: INTA, Estación Experimental Agropecuária Misiones, 1989. 11 p.

SANTIN, D.; BENEDETTI, E. L.; KASEKER, J. F.; BASTOS, M. C.; REISSMANN, C. B.; WENDLING, I.; BARROS, N. F. Nutrição e crescimento da erva-mate submetida à calagem. Ciência Florestal, Santa Maria, v. 23, p. 55 - 66, 2013.

SCHMITZ, J. A. K.; SOUZA, P. V. D.; KÄMPF, A. N. Propriedades químicas e físicas de substratos de origem mineral e orgânica para o cultivo de mudas em recipientes. Ciência Rural, Santa Maria, v. 32, p. 937 - 944, 2002.

SILVA, R. B. G.; SIMÕES, D.; SILVA, M. R. Qualidade de mudas clonais de Eucalyptus urophylla x E. grandis em função do substrato. Revista Brasileira de Engenharia Agrícola e Ambiental, Campina Grande, v. 16, p. 297 - 302, 2012.

TSAKALDIMI, M. Kenaf (Hibiscus cannabinus L.) core and rice hulls as components of container media for growing Pinus halepensis M. seedlings. Bioresource Technology, Philadelphia, v. 97, p. 1631 - 1639, 2006.

VAVRINA, C. S.; ARENAS, M.; CORNELL, J. A.; HANLON, E. A.; HOCHMUTH, G. J. Coiras an alternative to peat in media for tomato transplant production. Hort Science, Alexandria, v. 37, p. 309 312, 2002.

VERDONCK, O.; VLEESCHAUWER, D.; BOODT, M. de. The influence of the substrate to plant growth. Acta Horticulturae, Bélgica, n. 126, p. 251 - 258, 1981.

VIDOR, M. A.; RUIZ, C. P.; MORENO, S. V.; FLOSS, P. A. Variabilidade genética em um ensaio de progênies de erva-mate (Ilex paraguariensis St.-Hil.). Ciência Rural, Santa Maria, v. 32, p. 583 - 587, 2002.

WALLER, P. L.; WILSON, F. N. Evaluation of growing media for consumer use. Acta Horticulturae, Wagening, n. 150, p. $51-58,1984$.

WENDLING, I.; TRUEMAN, S. J.; XAVIER, A. Maturation and related aspects in clonal forestry - Part I: concepts, regulation and consequences of phase change. New Forest, West Lafayette, v. 45, p. 449 - 471, 2014.

WENDLING, I.; DUTRA, L. F.; GROSSI, F. Produção e sobrevivência de miniestacas e minicepas de erva-mate cultivadas em sistema semi-hidropônico. Pesquisa Agropecuária Brasileira, Brasília, v. 42, p. $289-292,2007 b$.

WENDLING, I.; GUASTALA, D; DEDECEK, R. Características físicas e químicas de substratos para produção de mudas de Ilex paraguariensis St.-Hil. Revista Árvore, Viçosa, v. 31, p. 209 - 220, 2007 a.

WENDLING, I.; XAVIER, A. Influência do ácido indolbutírico e da miniestaquia seriada no enraizamento e vigor de miniestacas de clones de Eucalyptus grandis. Revista Árvore, Viçosa, v. 29, 2005, p. 921 - 930.

ZANETTI, M.; CAZETTA, J. O.; MATTOS JÚNIOR, D.; CARVALHO, S. A. Uso de subprodutos de carvão vegetal na formação do porta-enxerto limoeiro 'Cravo' em ambiente protegido. Revista Brasileira de Fruticultura, Jaboticabal, v. 25, p. 508 - 512, 2003. 